\title{
Dietary energy density (ED) in Irish children aged 1 to 4 years
}

\author{
J. Walton, A. Gleeson, S. Lyons, S. Tyrell and A. Flynn \\ School of Food and Nutritional Sciences, University College Cork, Cork, Republic of Ireland
}

Few data are available investigating the ED of the diets of pre-school children. The aim of this paper was to use data from the Irish National Pre-School Nutrition Survey to determine nutrients and foods associated with dietary ED in $1-4$ year old children $(n=500)$. Food intake data collected by a 4 day weighed food record were analysed using a modified version of WISP ${ }^{\odot}$ (Tinuviel Software, Anglesey, UK) containing McCance and Widdowson's The Composition of Foods, $6^{\text {th }}$ Edition $^{(1)}$ and the Irish Food Composition Database $^{(2)}$.

Mean dietary ED (kcal/g) was calculated including (a) food only $(1.53 \mathrm{kcal} / \mathrm{g})$, (b) food \& milk (1.24 kcal/g), (c) food, milk \& fruit juices $(1.19 \mathrm{kcal} / \mathrm{g})(\mathrm{d})$ food and beverages $>5 \mathrm{kcal} / 100 \mathrm{~g}(1.13 \mathrm{kcal} / \mathrm{g})$ and (e) food and all beverages $(0.92 \mathrm{kcal} / \mathrm{g})$. For all methods, dietary ED increased with age from 1-4 years. Children were classified by tertile of their dietary ED (calculated using food and all beverages), stratified by age. Mean daily intakes of energy and (energy adjusted) nutrients and foods by tertile of dietary ED are reported.

\begin{tabular}{|c|c|c|c|c|}
\hline & & Dietary Energy Densit & & \\
\hline & Low $(n=166)$ & Medium $(n=168)$ & High $(n=166)$ & $P$ value \\
\hline Weight of food (g) & 619 & 601 & 587 & 0.585 \\
\hline Weight of beverages (g) & 847 & 681 & 507 & 0.000 \\
\hline Energy (kcal) & 1071 & 1145 & 1188 & 0.000 \\
\hline Protein (\%TE) & 15.4 & 15.2 & 15.0 & 0.343 \\
\hline Fat (\%TE) & 31.2 & 33.3 & 33.6 & 0.000 \\
\hline Saturated fat (\%TE) & 14.4 & 14.8 & 15.4 & 0.021 \\
\hline Carbohydrate (\% TE) & 50.8 & 49.0 & 48.3 & 0.000 \\
\hline Total sugars (\% TE) & 27.2 & 25.3 & 23.1 & 0.000 \\
\hline Non-milk sugars (\%TE) & 20.5 & 18.3 & 17.6 & 0.000 \\
\hline Dietary Fibre (g/1000 kcal) & 11.2 & 10.5 & 9.5 & 0.000 \\
\hline Food Groups (g/1000 kcal) & & & & \\
\hline White bread & 17.6 & 18.3 & 26.1 & 0.000 \\
\hline Ready-to-eat breakfast cereals & 23.1 & 18.4 & 14.3 & 0.272 \\
\hline Total milk & 300 & 305 & 228 & 0.001 \\
\hline Yoghurts and fromage frais & 58.0 & 54.0 & 56.5 & 0.737 \\
\hline Potatoes & 39.0 & 33.1 & 37.7 & 0.155 \\
\hline Fruit and juices & 191 & 170 & 126 & 0.000 \\
\hline Vegetables and vegetable dishes & 39.7 & 34.2 & 26.8 & 0.006 \\
\hline Total meat & 72.0 & 73.0 & 64.0 & 0.083 \\
\hline Biscuits and cakes & 13.2 & 12.9 & 17.7 & 0.002 \\
\hline Carbonated beverages (non-diet) & 9.5 & 6.7 & 6.0 & 0.875 \\
\hline Confectionary and savoury snacks & 10.3 & 11.9 & 12.7 & 0.161 \\
\hline
\end{tabular}

Children with lower ED diets compared with those with high ED diets consumed a similar amount of food (weight) but more beverages. They consumed less total energy and energy from fat (total and saturated) and more energy from carbohydrates and sugars (total and non-milk) and had more fibre dense diets. Their diet was higher in 'vegetables (including dishes)', 'fruit (including juices)' and milk and lower in white bread and 'biscuits and cakes'. On examination of the ED of the diet calculated using 'food only', all of the fore-mentioned associations still remained; furthermore lower ED diets were then also associated with higher intakes of yoghurts and ready-to-eat breakfast cereals, lower intakes of 'confectionary and savoury snacks' and non-diet carbonated beverages and a higher intake of protein.

Funded by the Irish Department of Agriculture, Food and the Marine under the Food for Health Research Initiative 2007-2012

1. Food Standards Agency (2002) The Composition of Foods $6^{\text {th }}$ edition.

2. Black LJ, Ireland J, Møller A et al. (2011) J Food Comp Anal 24, 1017-23. 